\section{Mikrosomales Ethanol-oxidierendes System}

\author{
A. M. Gressner ${ }^{1}$ und O. A. Gressner ${ }^{2}$ \\ ${ }^{1}$ Labor Dr. Wisplinghoff Berlin, Berlin, Deutschland \\ ${ }^{2}$ Labor Dr.Wisplinghoff Köln, Köln, Deutschland
}

Synonym(e) Cytochrom-P450-II-E1-System; MEOS

Englischer Begriff microsomal ethanol oxidizing system

Definition MEOS ist ein durch $\triangleright$ Ethanol induzierbares, am stärksten in den Mikrosomen der Leberzellen exprimiertes, Cytochrom P450 enthaltendes System des oxidativen Abbaus von Ethanol zu $>$ Acetaldehyd.

Beschreibung MEOS ist ein in den Mikrosomen der Hepatozyten, besonders der perivenösen Zone 3 des Azinus lokalisierter, Cytochrom $\mathrm{P} 450$-abhängiger, $\mathrm{NADPH}^{+}$als $>$Coenzym verbrauchender Stoffwechselweg des oxidativen Ethanolabbaus zu Acetaldehyd. Dieser Weg ist mit etwa 10-20\% am Ethanolabbau beteiligt. Durch den relativ hohen $\mathrm{K}_{\mathrm{m}}$-Wert von 7-10 mmol/L ist es erst bei höheren Ethanolkonzentrationen ( $>1,2 \mathrm{~g} / \mathrm{L}$ Serum bzw. $1,0 \mathrm{~g} / \mathrm{kg}$ Vollblut) für dessen Abbau im Vergleich zum Alkoholdehydrogenaseweg $\left(\mathrm{K}_{\mathrm{m}}\right.$ 0,2-2,0 $\left.\mathrm{mmol} / \mathrm{L}\right)$ ( $\triangleright$ Alkoholdehydrogenasen) bedeutsam. Das für den Abbau relevante Isoenzym, Cytochrom P450 II E1 (CYP II E1), ist durch chronische Ethanolzufuhr und einige Xenobiotika stark induzierbar und katalysiert folgende Reaktion:

$$
\begin{aligned}
& \mathrm{CH}_{3} \mathrm{CH}_{2} \mathrm{OH}+\mathrm{NADPH}+\mathrm{H}^{+}+\mathrm{O}_{2} \stackrel{\text { CYP IIEI }}{\rightleftarrows} \\
& \mathrm{CH}_{3} \mathrm{CHO}+\mathrm{NADP}^{+}+\mathrm{H}_{2} \mathrm{O}
\end{aligned}
$$

Außer Ethanol werden auch Acetaldehyd und über 80 toxikologisch wichtige $>$ Xenobiotika oxidativ abgebaut. Die hohe Monooxygenaseaktivität ist pathophysiologisch bedeutsam für die Peroxidation von $>$ Fettsäuren und Membranlipiden in Gegenwart geringer Eisenkonzentrationen. Da MEOS besonders in der perivenösen Zone 3 der metabolischen Zonierung des Leberazinus konzentriert ist, erklärt sich auch die dortige Frühlokalisation alkoholischer Leberschädigungen durch Acetaldehyd. Außer in Hepatozyten der Leber ist MEOS mit geringer Expression auch in den Mukosazellen des oberen Gastrointestinaltrakts, der Niere und Lunge nachweisbar.

\section{Literatur}

Kessova I, Cederbaum AI (2003) CYP2E1: biochemistry, toxicology, regulation and function in ethanol-induced liver injury. Curr Mol Med 3:509-518

Lieber CS (2004) The discovery of the microsomal ethanol oxidizing system and its physiologic and pathologic role. Drug Metab Rev 36:511-529

Villeneuve JP, Pichette V (2004) Cytochrome P450 and liver diseases. Curr Drug Metab 5:273-282 